\title{
Infertility and Pregnancy Loss in Hispanic/Latino Women with Chronic Kidney Disease: Results from the Hispanic Community Health Study/ Study of Latinos (HCHS/SOL)
}

Monica Reynolds ( $\sim$ monica_reynolds@med.unc.edu )

University of North Carolina at Chapel Hill https://orcid.org/0000-0002-9988-8833

\section{Laura R Loehr}

University of North Carolina at Chapel Hill

\section{Susan L Hogan}

University of North Carolina at Chapel Hill

Yichun Hu

University of North Carolina at Chapel Hill

\section{Carmen R Isasi}

Albert Einstein Medical Center

\section{Christina Cordero}

University of Miami

\section{Ana C Ricardo}

University of Illinois at Chicago College of Medicine

\section{James P Lash}

University of Illinois at Chicago College of Medicine

\section{Vimal K Derebail}

University of North Carolina at Chapel Hill

\section{Research article}

Keywords: Chronic kidney disease, infertility, pregnancy, Hispanic/Latino, pregnancy loss

Posted Date: December 14th, 2020

DOI: https://doi.org/10.21203/rs.3.rs-48556/v2

License: (c) (i) This work is licensed under a Creative Commons Attribution 4.0 International License. Read Full License 


\section{Abstract}

Background: Hispanic/Latino individuals are less likely to receive optimal treatment for chronic kidney disease (CKD) than non-Hispanic whites. This may be particularly detrimental for women of reproductive age as CKD may increase risk for infertility, menstrual irregularities, and pregnancy loss. While these maternal outcomes have been associated with advanced CKD, their occurrence in mild CKD is unclear.

Methods: Using baseline (2008-2011) and second study visit (2014-2017) data from the Hispanic Community Health Study/Study of Latinos (HCHS/SOL), we assessed the association between CKD and self-reported infertility, cessation of menses, hysterectomy, and nonviable pregnancy loss (experienced at less than 24 weeks gestation) in women of reproductive age (18-45 years). Multivariable survey logistic regression analyses were used to compute prevalence odds ratios with $95 \%$ confidence intervals (OR, 95\% Cl).

Results: Of the 2,589 women included (mean age 31.4 years), 4.6\% were considered to have CKD. In adjusted analyses, women with CKD did not have a significantly increased odds of infertility (OR 1.02, 95\% Cl 0.42 - 2.49 ), cessation of menses (OR 1.25, 95\% Cl 0.52 - 3.04) or hysterectomy (OR 1.17, 95\% Cl $0.61-2.25)$ compared to those without CKD. In those with CKD, the adjusted odds of a nonviable pregnancy loss was increased when considering pregnancies occurring after baseline visit (OR 2.11, 95\% Cl $0.63-7.02)$ but not statistically significance.

Conclusion: In our Hispanic/Latino cohort, the presence of mild CKD did not confer an additional risk of our outcomes of interest. Examining nonviable pregnancy loss after CKD diagnosis in a larger sample warrants further study.

\section{Background}

Impaired fertility, menstrual irregularities, and early menopause have been commonly described in women with advanced chronic kidney disease (CKD) including those on dialysis. These conditions are thought to be related to uremic toxins and an altered gonadal axis, resulting in hyperprolactinemia and a reduced cyclic surge of luteinizing and follicle stimulating hormones.[1-7] Women with end-stage kidney disease (ESKD) appear to have higher rates of early pregnancy loss.[8] While this may in part be related to higher rates of comorbid conditions such as obesity, diabetes, and hypertension, a uremic milieu likely also plays a role.[9-12] The prevalence of impaired fertility, cessation of menses and early pregnancy loss in women with mild CKD has not been well described.

Hispanic/Latinos in the United States (U.S). are less likely to be screened for kidney disease risk factors or receive optimal treatment for CKD after diagnosis. $[13,14]$ They account for a nearly $40 \%$ higher prevalence rate of ESKD than non-Hispanic whites and may experience increased risk of progression to ESKD.[15, 16] In the Hispanic Community Health Study/Study of Latinos (HCHS/SOL), a prospective study of over 16,000 individuals throughout the U.S., the prevalence of CKD in all women (aged 18-74 years) was 13\% and disease unawareness for men and women combined reached 18\%.[17] Given the above, disease unawareness and lack of treatment could be particularly detrimental for Hispanic/Latino women of reproductive age. Indeed, minority women in the U.S. are disproportionately affected by the rising rates of early pregnancy loss.[18, 19] This has significant clinical implications as early pregnancy loss has been associated with anxiety, depression, and post-traumatic stress disorder.[20]

To uniquely assess the impact of mild CKD on fertility and early pregnancy loss in a high-risk cohort, we performed a secondary analysis of data from the HCHS/SOL baseline (2008-2011) and second study visit (2014-2017). We sought to assess the prevalence of CKD in Hispanic/Latino women of reproductive age (18 - 45 years old) as well as 
the separate associations between CKD and infertility, cessation of menses, hysterectomy (as a marker for abnormal uterine bleeding), and nonviable pregnancy loss (experienced at less than 24 weeks gestation).

\section{Methods}

\section{Study population}

The HCHS/SOL is a population-based cohort of 16,415 Hispanic/Latinos aged 18-74 years from 9,872 randomly selected households in four U.S. field communities (Bronx, New York; Chicago, Illinois; Miami, Florida; and San Diego, California). The sample design and cohort selection have been previously described.[21, 22] Briefly, a stratified twostage area probability sample of household addresses was selected in each community. The first sampling stage randomly selected census block groups with stratification based on Hispanic/Latino concentration and proportion of high/low socioeconomic status. The second sampling stage randomly selected households, with stratification, from U.S. Postal Service registries that covered the randomly selected census block groups. Sampling weights were generated to reflect the probabilities of selection at each stage.

At the baseline visit (2008 - 2011), 4,119 women were in the reproductive age range defined as ages of 18 - 45 years old. Of these, 2,810 women returned for a second study visit between 2014 and 2017 . Women were eligible for the present analysis if they provided serum and/or urine samples at both visits (for CKD determination) and completed the reproductive and medical history questionnaire administered at the second study visit $(n=2,589)$.

The HCHS/SOL study adheres to the Declaration of Helsinki and was approved by the institutional review boards at each field center where all participants gave written consent at each study visit.

\section{Data collection}

Each study visit included clinical measurements, fasting venous blood collection and spot urine specimens. Participants were asked to bring all current medications to each visit. Questionnaires were used to obtain information on demographic factors, acculturation, medical, and social history. At the second visit, all women were asked to complete a reproductive and medical history questionnaire and a pregnancy complication questionnaire (see Additional file 1 and 2 for included questionnaires). The information obtained from these questionnaires included events occurring both before and after the baseline visit.

\section{Exposure Assessment}

Serum creatinine was measured on a Roche Modular P Chemistry Analyzer using a creatinase enzymatic method (Roche Diagnostics, Indianapolis, IN) and was isotope dilution mass spectrometry traceable. Urine albumin was measured using an immunoturbidimetric method on the ProSpec nephelometric analyzer (Dade Behring $\mathrm{GmbH}$, Marburg, Germany). Estimated glomerular filtration rate (eGFR) was calculated using the Chronic Kidney Disease Epidemiology Collaboration (CKD-EPI) equation from serum creatinine, gender, age and race (black or non-black).[23] CKD was typically defined by either a low eGFR $\left(<60 \mathrm{ml} / \mathrm{min}\right.$ per $\left.1.73 \mathrm{~m}^{2}\right)$ or a urine albumin to creatinine ratio (UACR) of $>30 \mathrm{mg} / \mathrm{g}$ on spot urine samples at both visits. However, given our younger cohort and noted variability in measurements from two visits, we expanded our definition of CKD to include the following: a) if a participant's eGFR was $<60 \mathrm{ml} / \mathrm{min}$ per $1.73 \mathrm{~m}^{2}$ at one visit and $<70 \mathrm{ml} / \mathrm{min}$ per $1.73 \mathrm{~m}^{2}$ at another, $\mathrm{b}$ ) if a participant's UACR was > $300 \mathrm{mg} / \mathrm{g}$ (considered macroalbuminuria/ severely increased albuminuria) at either visit, and c) if at baseline visit, a participant's UACR $>30 \mathrm{mg} / \mathrm{g}$ while taking an angiotensin converting enzyme-inhibitor (ACE-I) or angiotensin receptor blocker (ARB) and $<30 \mathrm{mg} / \mathrm{g}$ at the subsequent visit. In our primary analysis, we utilized this broader definition of 
CKD. A sensitivity analysis in which we limited our definition to only those with a low eGFR $\left(<60 \mathrm{ml} / \mathrm{min} \mathrm{per} 1.73 \mathrm{~m}^{2}\right)$ or UACR $>30 \mathrm{mg} / \mathrm{g}$ at both visits was also performed.

\section{Outcome Assessment}

In the reproductive questionnaire, infertility was assessed with the question, "Have you ever tried to become pregnant for greater than one year without success?" and women were also asked to report the perceived cause of their infertility (medical problem in themselves, their partner, or both). Cessation of menses was assessed ("Have your natural periods stopped permanently?") as well as the reason why it occurred. All women were asked to report a history of hysterectomy. Women reported their total number of pregnancies and how many occurred before or after the baseline visit. Early pregnancy losses occurring before the baseline visit were specified as miscarriage vs tubal/ectopic vs elective termination (derived) but were combined as pregnancies lasting less than 24 weeks in the administered survey when occurring after baseline visit (see Additional file 1).

\section{Covariates}

Covariates from the baseline visit included age, body mass index (BMI), hypertension and diabetes. Each study visit collected the participant's date of birth, standing height and weight. Hypertension was defined as a sitting systolic blood pressure $140 \mathrm{mmHg}$, diastolic blood pressure $90 \mathrm{mmHg}$, or use of an antihypertensive medication (documented or self-reported use of an antihypertensive medication). Diabetes mellitus was defined as fasting plasma glucose of $126 \mathrm{mg} / \mathrm{dl}$, 2-hour post-load glucose levels of $200 \mathrm{mg} / \mathrm{dl}$, a hemoglobin A1c level of $6.5 \%$, or selfreported diabetes.

\section{Statistical Analyses}

Summary statistics, prevalence estimates, and odds ratios were weighted to adjust for sampling probability and nonresponse.[21, 22] All analyses account for cluster sampling and the use of stratification in sample selection. Survey-specific procedures were used in all analyses to account for the two-stage sampling design, stratification, and clustering. Descriptive statistics including mean \pm standard deviation and counts and percentages were employed to characterize differences among women with CKD versus those without. Bivariate analysis included Chi-square tests for categorical variables and adjusted Wald tests for continuous variables. We used survey logistic regression analyses to determine the unadjusted and multivariable-adjusted associations between CKD and the separate outcomes of infertility, cessation of menses, hysterectomy and nonviable pregnancy loss (less than 24 weeks gestation). A sensitivity analysis restricted the definition of CKD to women with either a low eGFR $(<60 \mathrm{ml} / \mathrm{min} \mathrm{per}$ $\left.1.73 \mathrm{~m}^{2}\right)$ or a UACR of $>30 \mathrm{mg} / \mathrm{g}$ at both visits $(\mathrm{n}=96)$.

Due to the limited number of outcome events, we assessed the influence of potential confounders one at a time to ensure model convergence. Covariates considered included participant's age, BMI, presence of diabetes and hypertension at baseline study visit. For each study outcome, we used a 10\% change in estimate approach for final covariate selection. Prevalence odds ratios and their $95 \%$ confidence intervals (OR, 95\% Cls) were computed. All statistical tests were two-sided with a significance level of 0.05. Analyses were performed using Stata software (version 15.1; StataCorp LLC, College Station, TX, USA).

\section{Results}

\section{Study Cohort Characteristics}


A total of 2,589 women met study selection criteria and were included in the analysis (Figure 1).

Of these individuals, 120 (4.6\%) women were classified as having CKD according to our primary definition. Table 1a displays the characteristics of the study cohort at the baseline study visit, both overall and stratified by CKD status. The mean age was $31.4 \pm 8.3$ years old and most women (44.3\%) identified their heritage/ethnicity as Mexican, followed by Cuban (14.5\%) and Puerto Rican (12.7\%). Compared to those without CKD, women with CKD were older (35.1 vs 31.2 years old) and had a higher BMI (33.4 kg/m² vs $29.3 \mathrm{~kg} / \mathrm{m}^{2}$ ). Fewer women with CKD had received a high school diploma or more compared to those without CKD (65.7\% vs 73.1\%). Women with CKD had over three times the prevalence of diabetes (25.5\% vs $7.0 \%)$ and over four times the prevalence of hypertension (30.7\% vs $6.7 \%)$ compared to those without CKD. The average time between baseline and second study visit was 6.2 years for both groups.

Table 1a. HCHS/SOL Baseline Visit (2008-2011) Characteristics of All Reproductive Age Women and by CKD status 


\begin{tabular}{|c|c|c|c|}
\hline Characteristic & $\begin{array}{l}\text { Overall } \\
n=2,589\end{array}$ & $\begin{array}{l}\text { Without CKD } \\
n=2,469\end{array}$ & $\begin{array}{l}\text { With CKD } \\
n=120\end{array}$ \\
\hline *Age (years) & $31.4 \pm 8.3$ & $31.2 \pm 8.3$ & $35.1 \pm 7.7$ \\
\hline${ }^{*} \mathrm{BMI}\left(\mathrm{kg} / \mathrm{m}^{2}\right)$ & $29.5 \pm 7.1$ & $29.3 \pm 7.1$ & $33.4 \pm 7.4$ \\
\hline \multicolumn{4}{|l|}{ Heritage/Ethnicity (\%) } \\
\hline Central American & 8.1 & 7.9 & 12.6 \\
\hline Cuban & 14.5 & 14.7 & 9 \\
\hline Dominican & 11.4 & 11.4 & 10.5 \\
\hline Mexican & 44.3 & 44.1 & 47.3 \\
\hline Puerto Rican & 12.7 & 12.6 & 14.6 \\
\hline South American & 4.3 & 4.5 & 1 \\
\hline More than one & 4.7 & 4.7 & 5 \\
\hline High school diploma or more (\%) & 72.8 & 73.1 & 65.7 \\
\hline Cigarette use (past or current) (\%) & 23.3 & 23.3 & 22.1 \\
\hline Alcohol use (past or current) (\%) & 77.6 & 77.8 & 74.3 \\
\hline *Diabetes (\%) & 7.8 & 7.0 & 25.5 \\
\hline *Hypertension (\%) & 7.8 & 6.7 & 30.7 \\
\hline Average systolic BP (mmHg) & $108.5 \pm 12.4$ & $108.2 \pm 12.0$ & $115.9 \pm 18.3$ \\
\hline Average diastolic BP (mmHg) & $68.6 \pm 10.1$ & $68.3 \pm 9.8$ & $74.8 \pm 14.1$ \\
\hline ACE-I/ARB at baseline visit (\%) & 3.5 & 2.7 & 20.2 \\
\hline Creatinine (mg/dL) & $0.70 \pm 0.1$ & $0.70 \pm 0.1$ & $0.76 \pm 0.3$ \\
\hline *Estimated GFR (mL/min/1.73m²) & $111.7 \pm 16.2$ & $112.0 \pm 15.7$ & $104.2 \pm 24.7$ \\
\hline *Urine albumin to creatinine ratio $(\mathrm{mg} / \mathrm{g})$ & $6.7(4.8-11.3)$ & $6.5(4.7-10.5)$ & $77.6(42.1-284.7)$ \\
\hline
\end{tabular}

*Statistically significant $(p<0.05)$ difference between women without CKD and women with CKD

Data are mean \pm standard deviation or percent except for urine albumin to creatinine ratio which is median (interquartile range)

Abbreviations: HCHS/SOL, Hispanic Community Health Study, Study of Latinos; BMI, body mass index; BP, blood pressure; ACE-I/ARB, angiotensin converting enzyme inhibitor/ angiotensin II receptor blocker; GFR, glomerular filtration rate

The majority (67.5\%) of women with CKD met criteria for CKD based on persistently elevated UACR at both visits while $12.5 \%$ met criteria due to a eGFR $<60 \mathrm{ml} / \mathrm{min} / 1.73 \mathrm{~m}^{2}$ at both visits or an elevated UACR at one visit and low 
eGFR at another (Table 1b). An additional $20 \%$ were considered to have CKD through one of the expanded definitions.

Table 1b. Distribution of CKD measures: eGFR by albuminuria category at Visit 1 and Visit 2 in Reproductive Age Women in HCHS/SOL $(\mathrm{N}=2,589)$

\begin{tabular}{|llll|}
\hline Visit 1 & UACR $<30 \mathrm{mg} / \mathrm{g}$ & UACR $30-300 \mathrm{mg} / \mathrm{g}$ & UACR $>300 \mathrm{mg} / \mathrm{g}$ \\
\hline GFR $>60$ & 2337 & 213 & 21 \\
\hline GFR $30-60$ & 9 & 3 & 3 \\
\hline GFR $<30$ & 0 & 1 & 2 \\
\hline Visit 2 & & & \\
\hline GFR $>60$ & 2371 & & 29 \\
\hline GFR $30-60$ & 2 & 178 & 3 \\
\hline GFR $<30$ & 0 & 2 & 2 \\
\hline Missing eGFR & & 0 & 2 \\
\hline
\end{tabular}

eGFR in $\mathrm{mL} / \mathrm{min} / 1.73 \mathrm{~m}^{2}$

Abbreviations: CKD, chronic kidney disease; eGFR, estimated glomerular filtration rate; HCHS/SOL, Hispanic Community Health Study, Study of Latinos; UACR urine albumin to creatinine ratio

The median (interquartile range) UACR of those with CKD at the baseline visit was 77.6 (42.1- 284.7) $\mathrm{mg} / \mathrm{g}$ and was 123.8 (36.4- 493.9) $\mathrm{mg} / \mathrm{g}$ at the second visit compared to $6.5(4.7-10.5) \mathrm{mg} / \mathrm{g}$ and $4.1(2.5-7.9) \mathrm{mg} / \mathrm{g}$ at baseline and second visit in those without CKD.

\section{CKD and infertility, cessation of menses, and hysterectomy}

Infertility was reported by $15.0 \%$ of women with CKD and $12.8 \%$ of women without CKD. Of those who responded to a follow-up question of the perceived cause of their infertility $(n=142)$, all women with CKD reported their infertility was due to either a medical problem in themselves or both themselves and their partner (vs. their partner alone). A small percentage of women without CKD (7.5\%) reported their infertility was due to their partner alone. Cessation of menses was reported by $26.7 \%$ of women with CKD and $14.5 \%$ of women without CKD at similar mean (41.3 vs 41.8$)$ and median (44 (37-47) vs 44 (39-47)) ages. Reasons cited for amenorrhea included "They stopped naturally" (44.3\% of women with CKD vs $48.3 \%$ of women without CKD), "Surgery to remove ovaries or uterus" (26.0\% CKD vs $38.9 \%$ without CKD), and "Other" (29.6\% CKD vs $10.5 \%$ without CKD). A history of hysterectomy was reported by $7.1 \%$ of women with CKD and $6.1 \%$ of women without CKD. 
Table 2 compares the prevalence odds ratios for self-reported infertility, cessation of menses, and hysterectomy in women with vs. without CKD. Compared to women without CKD, those with CKD did not have a significantly increased odds of infertility (adjusted OR $1.02,95 \% \mathrm{Cl} 0.42-2.49$ ). In a crude comparison, women with CKD had twice the odds of experiencing cessation of menses (OR 2.15, 95\% $\mathrm{Cl} 1.15-4.0$ ) but this was attenuated and no longer significant after adjustment for age and BMI (OR 1.25, 95\% Cl $0.52-3.04$ ). The odds of hysterectomy were not statistically different between women with vs. without CKD (OR 1.17, 95\% Cl $0.61-2.25$ ) and an adjusted analysis was not performed due to the low number of events. In the sensitivity analyses, the prevalence odds ratios were higher for infertility, cessation of menses, and hysterectomy in women with CKD but the estimates were not substantially different from the base analysis and were not statistically significant (Table 2).

Table 2. Multivariable Adjusted Association Between CKD and Self-reported Infertility, Cessation of Menses, and Hysterectomy Among Reproductive Age Women in the HCHS/SOL

\begin{tabular}{|c|c|c|c|c|c|c|c|}
\hline \multicolumn{8}{|c|}{ Primary analyses } \\
\hline \multirow{3}{*}{ Characteristic } & \multirow{3}{*}{$\mathrm{n}$} & \multicolumn{2}{|l|}{ Infertility } & \multicolumn{2}{|c|}{ Cessation of Menses } & \multicolumn{2}{|c|}{ Hysterectomy } \\
\hline & & Unadjusted & Adjusted $^{\mathrm{a}}$ & Unadjusted & Adjusted $^{b}$ & Unadjusted & Adjusted \\
\hline & & $\begin{array}{l}\text { OR }(95 \% \\
\mathrm{Cl})\end{array}$ & $\begin{array}{l}\text { OR }(95 \% \\
\mathrm{Cl})\end{array}$ & $\begin{array}{l}\mathrm{OR}(95 \% \\
\mathrm{Cl})\end{array}$ & $\begin{array}{l}\text { OR }(95 \% \\
\mathrm{Cl})\end{array}$ & $\begin{array}{l}\text { OR }(95 \% \\
\text { Cl) }\end{array}$ & $\begin{array}{l}\text { OR }(95 \% \\
\mathrm{Cl})\end{array}$ \\
\hline No CKD & 2,469 & Ref. & Ref. & Ref. & Ref. & Ref. & Ref. \\
\hline CKD & 120 & $\begin{array}{l}1.20(0.49 \\
-2.95)\end{array}$ & $\begin{array}{l}1.02 \\
(0.42- \\
2.49)\end{array}$ & $\begin{array}{l}2.15(1.15- \\
4.00)\end{array}$ & $\begin{array}{l}1.25 \\
(0.52- \\
3.04)\end{array}$ & $\begin{array}{l}1.17(0.61- \\
2.25)\end{array}$ & NA \\
\hline \multicolumn{8}{|c|}{ Sensitivity analyses ${ }^{c}$} \\
\hline & & \multicolumn{2}{|l|}{ Infertility } & \multicolumn{2}{|c|}{ Cessation of Menses } & \multicolumn{2}{|c|}{ Hysterectomy } \\
\hline \multirow[t]{2}{*}{ Characteristic } & $\mathbf{n}$ & Unadjusted & Adjusted $^{\mathrm{a}}$ & Unadjusted & Adjusted $^{b}$ & Unadjusted & Adjusted \\
\hline & & $\begin{array}{l}\text { OR }(95 \% \\
\mathrm{Cl})\end{array}$ & $\begin{array}{l}\text { OR }(95 \% \\
\mathrm{Cl})\end{array}$ & $\begin{array}{l}\text { OR }(95 \% \\
\mathrm{Cl})\end{array}$ & $\begin{array}{l}\text { OR }(95 \% \\
\mathrm{Cl})\end{array}$ & $\begin{array}{l}\text { OR }(95 \% \\
\mathrm{Cl})\end{array}$ & $\begin{array}{l}\text { OR }(95 \% \\
\mathrm{Cl})\end{array}$ \\
\hline No CKD & 2,493 & Ref. & Ref. & Ref. & Ref. & Ref. & Ref. \\
\hline CKD & 96 & $\begin{array}{l}1.41(0.54- \\
3.69)\end{array}$ & $\begin{array}{l}1.19 \\
(0.46- \\
3.10)\end{array}$ & $\begin{array}{l}2.66(1.36- \\
5.20)\end{array}$ & $\begin{array}{l}1.74 \\
(0.66- \\
4.61)\end{array}$ & $\begin{array}{l}1.35(0.66- \\
2.77)\end{array}$ & NA \\
\hline
\end{tabular}

Abbreviations: CKD, chronic kidney disease; HCHS/SOL, Hispanic Community Health Study, Study of Latinos; OR, odds ratio; $\mathrm{Cl}$, confidence interval; Ref, referent; NA, not applicable.

Adjusted OR for hysterectomy not performed due to a low number of events

${ }^{\text {a }}$ Adjusted for BMl

${ }^{\mathrm{b}}$ Adjusted for age and BMI 
${ }^{c}$ In the sensitivity analysis, CKD was defined as either a low eGFR $\left(<60 \mathrm{ml} / \mathrm{min}\right.$ per $\left.1.73 \mathrm{~m}^{2}\right)$ or a urine albumin to creatinine ratio of $>30 \mathrm{mg} / \mathrm{g}$ on spot urine samples at both visits

\section{CKD and pregnancy loss}

At the second visit, $92.9 \%(n=112)$ of women with CKD and $85.4 \%(n=2165)$ of women without CKD reported a history of pregnancy (Figure 1 ). A total of $45.9 \%$ of women ( $42.3 \%$ of women with CKD and $46.1 \%$ of women without CKD) reported a history of nonviable loss. As shown in Table 3, the presence of CKD was not associated with an increased risk of a nonviable pregnancy loss (adjusted OR $0.89,95 \% \mathrm{Cl} 0.53-1.48$ ). The risk appeared to increase when assessing only those women who reported pregnancy occurring after baseline visit (adjusted OR 2.11, $95 \% \mathrm{Cl} 0.63$ 7.02) though this was imprecise and not statistically significant. A sensitivity analysis using the restricted CKD definition showed similar results (Table 3 ). In addition, we repeated our analyses excluding those with GFR $<60$ $\mathrm{ml} / \mathrm{min}$ per $1.73 \mathrm{~m}^{2}$ at either visit and noted similar results (data not shown).

Table 3. Association Between CKD and Nonviable Pregnancy Loss Among Reproductive Age Women in the HCHS/SOL

\begin{tabular}{|c|c|c|c|c|}
\hline \multicolumn{5}{|c|}{ Primary analyses } \\
\hline & \multicolumn{2}{|c|}{$\begin{array}{l}\text { Nonviable loss among women with } \\
\text { history of pregnancy at any time } \\
(n=2277)\end{array}$} & \multicolumn{2}{|c|}{$\begin{array}{l}\text { Nonviable loss among women } \\
\text { reporting pregnancy after baseline visit } \\
(n=630)\end{array}$} \\
\hline & Unadjusted & Adjusted $^{a}$ & Unadjusted & Adjusted $^{b}$ \\
\hline Characteristic & OR $(95 \% \mathrm{Cl})$ & OR $(95 \% \mathrm{Cl})$ & OR (95\% Cl) & OR $(95 \% \mathrm{Cl})$ \\
\hline No CKD & Ref. & Ref. & Ref. & Ref. \\
\hline CKD & $0.86(0.52-1.43)$ & $0.89(0.53-1.48)$ & $1.81(0.56-5.90)$ & $2.11(0.63-7.02)$ \\
\hline \multicolumn{5}{|c|}{ Sensitivity analyses ${ }^{c}$} \\
\hline & \multicolumn{2}{|c|}{$\begin{array}{l}\text { Nonviable loss among women with } \\
\text { history of pregnancy at any time } \\
(n=2277)\end{array}$} & \multicolumn{2}{|c|}{$\begin{array}{l}\text { Nonviable loss among women } \\
\text { reporting pregnancy after baseline visit } \\
(n=630)\end{array}$} \\
\hline & Unadjusted & Adjusted $^{a}$ & Unadjusted & Adjusted $^{b}$ \\
\hline Characteristic & OR $(95 \% \mathrm{Cl})$ & OR $(95 \% \mathrm{Cl})$ & OR (95\% Cl) & OR $(95 \% \mathrm{Cl})$ \\
\hline No CKD & Ref. & Ref. & Ref. & Ref. \\
\hline CKD & $0.88(0.49-1.60)$ & $0.91(0.50-1.66)$ & $1.66(0.43-6.36)$ & $1.80(0.48-6.81)$ \\
\hline
\end{tabular}

Abbreviations: CKD, chronic kidney disease; HCHS/SOL, Hispanic Community Health Study, Study of Latinos; OR, odds ratio; $\mathrm{Cl}$, confidence interval; Ref, referent.

a Adjusted for BMI 
${ }^{\mathrm{b}}$ Adjusted for Diabetes

${ }^{c}$ In the sensitivity analysis, CKD was defined as either a low GFR $\left(<60 \mathrm{ml} / \mathrm{min}\right.$ per $\left.1.73 \mathrm{~m}^{2}\right)$ or a urine albumin to creatinine ratio of $>30 \mathrm{mg} / \mathrm{g}$ on spot urine samples at both visits

\section{Discussion}

With a focus on a minority population that is often undertreated and underrepresented in research, our study builds upon prior literature evaluating the impact of CKD on women's fertility and reproductive health. Assessing these outcomes in even mild CKD is prudent given their clinical significance. Infertility is a global public health issue and can lead to significant psychological distress.[24] Early menopause is associated with both ischemic cardiovascular disease and increased mortality.[25] Taking into account comorbidities such as obesity and diabetes that are also known to be associated with menstrual irregularities and infertility,[26, 27] our study provides support that mild CKD may not be associated with increased risk.

Previous research has demonstrated that dysfunctional uterine bleeding, menorrhagia, and amenorrhea are common in women with advanced CKD. $[3,28,29]$ Given this, we hypothesized that women with CKD may be at higher risk for undergoing hysterectomy compared to those without CKD. Unfortunately, the small number of events here limited statistical power. In a larger population, data from the Women's Health Initiative found no difference in prevalence of hysterectomy in women with CKD vs women without CKD $(1.2 \%$ vs $2.0 \%, p=0.16)$ though women with CKD more likely to have had menopause before age 45 years $(26 \%$ vs $23 \%, p=0.02)$.[30]

Spontaneous abortion, or miscarriage, is the most common complication in early pregnancy, and the incidence in clinically recognized pregnancies is between 8 - 20\%.[31, 32] Well-known risk factors include maternal age over 35 years old, previous spontaneous abortion and maternal smoking, though minority women, including Hispanic/Latino women, may also be at higher risk for miscarriage.[19] Our study seemed to suggest this as well, with $45.9 \%$ of parous women reporting at least one nonviable loss (pregnancy loss before 24 weeks). The rates of nonviable pregnancy loss in women with CKD are not well described. In those with advanced CKD or requiring dialysis, the blood urea nitrogen level is inversely related to the length of gestation and offspring's birth weight.[33] For those with milder CKD, it is unclear if mechanisms aside from uremic toxins increase risk of early loss. Although women who receive a kidney transplant can often see a rapid return of fertility, reported miscarriage rates range between 15.4 $45 \%$ in this population.[34-36] In the general population, elevated preconception maternal blood pressure has been found to increase the risk of miscarriage.[11] Though 30.7\% of our CKD cohort were considered to have hypertension, it did not emerge as a strong confounder in our final model when assessing risk for nonviable pregnancy loss.

There are several limitations to our study. In our young, reproductive age women from the HCHS/SOL, CKD was mostly defined by persistent albuminuria and was present in a small number $(4.6 \%$ of women included), which ultimately limited the power of our analyses. While the percent of Hispanic/Latino women of reproductive age with CKD is largely unknown, prior literature has estimated CKD affects $6 \%$ of all reproductive age women.[37] To confirm true chronic kidney disease, we were able to utilize measurements from two study visits, approximately 6.2 years apart. However, borderline values in CKD measurements existed when using a strict cutoff estimated GFR of $<60$ $\mathrm{ml} / \mathrm{min}$ per $1.73 \mathrm{~m}^{2}$ and UACR ratio $>30 \mathrm{mg} / \mathrm{g}$. To include mild CKD, we broadened our definition to include those with an estimated GFR $<60 \mathrm{ml} / \mathrm{min}$ per $1.73 \mathrm{~m}^{2}$ at one visit and $<70 \mathrm{ml} / \mathrm{min}$ per $1.73 \mathrm{~m}^{2}$ at another as we felt this was still a significantly low GFR to constitute CKD in this young population. We also included those with a UACR > $300 \mathrm{mg} / \mathrm{g}$ at either visit as this is considered a clinical cutoff for severely increased albuminuria which has been shown to be a risk marker for CKD progression.[38-40] Finally, we included women with a UACR > $30 \mathrm{mg} / \mathrm{g}$ at 
baseline visit while taking an ACE-I or ARB but UACR $<30 \mathrm{mg} / \mathrm{g}$ at the second visit, as we felt this discrepancy could be explained by the anti-proteinuric effects of the medications. Sensitivity analyses performed with a stricter definition of CKD as either an estimated GFR $<60 \mathrm{ml} / \mathrm{min}$ per $1.73 \mathrm{~m}^{2}$ or UACR $>30 \mathrm{mg} / \mathrm{g}$ at both visits $(\mathrm{n}=96)$ showed similar odds ratios among women with CKD.

Importantly, the timing of CKD onset was unknown as we only had measurements from the baseline and second study visit. This may help account for why we did not see an increased risk for nonviable pregnancy loss occurring at any time but did see higher odds ratios in women with CKD when examining pregnancies that occurred specifically after baseline visit. Likewise, the specific dates of pregnancy losses were not provided and only reported as either before or after baseline visit. Thus, while pregnancy could have occurred very close to the baseline visit, for some individuals a nonviable pregnancy loss could have occurred many years prior to the baseline visit. We therefore cannot be fully certain that CKD specifically preceded the loss and as such, only prevalence odds ratios could be performed. Data from the Nurses' Health Study II suggests that early pregnancy loss (especially those between 12 19 weeks) may be associated with increased risk for future type 2 diabetes, hypercholesterolemia, and hypertension. [41] As such, it could be hypothesized that pregnancy loss may also contribute to future CKD by way of an increased burden of CKD risk factors.

Finally, the women's health and reproductive outcomes gathered were self-reported and thus subject to recall bias and/or inaccurate reporting. While infertility was assessed in all women by asking whether they had "ever tried to become pregnant for greater than one year without success", it is currently recognized that for women older 35 years old, this interval should be shortened to six months.[42] Cessation of menses was assessed by asking whether natural periods had ended but this was not confirmed with biochemical evidence and does not include women who may be menstruating but having anovulatory cycles, a condition that is common in CKD.

\section{Conclusion}

The presence of mild CKD by our definition did not confer a significant risk of infertility, cessation of menses, or hysterectomy in this Hispanic/Latino cohort. Among women who experienced pregnancy after the baseline study visit, those with CKD had higher adjusted point estimates for nonviable pregnancy loss though this failed to reach statistical significance. Overall, knowledge of pre-pregnancy kidney function and its comorbidities may aid in reproductive counseling and allow for medical optimization before attempting to conceive. Likewise, evaluating for underlying CKD in Hispanic/Latino women who experience nonviable pregnancy loss may also be prudent. Larger prospective studies of women with all stages of CKD attempting to conceive are warranted.

\section{Abbreviations}

HCHS/SOL- Hispanic Community Health Study/Study of Latinos; CKD- chronic kidney disease; ESKD- end-stage kidney disease; U.S.- United States; BMI- body mass index; UACR- urine albumin to creatinine ratio; eGFR- estimated glomerular filtration rate; ACE-I- angiotensin converting enzyme-inhibitor; ARB- angiotensin receptor blocker

\section{Declarations}

Ethics approval and consent to participate: The HCHS/SOL study adheres to the Declaration of Helsinki and was approved by the institutional review boards at each field center where all participants gave written consent at each study visit. This secondary data analysis was reviewed by the University of North Carolina Office of Human Research Ethics and deemed non-human subjects research due to the de-identification of data. 
Consent for publication: Not applicable.

Availability of data and materials: The data that support the findings of this study are available from $\mathrm{HCHS} / \mathrm{SOL} b y$ permission. Data are available from the authors upon reasonable request and with permission of HCHS/SOL.

Competing interests: The authors declare that they have no competing interests

Funding: The Hispanic Community Health Study/Study of Latinos is a collaborative study supported by contracts from the National Heart, Lung, and Blood Institute (NHLBI) to the University of North Carolina (HHSN268201300001I / N01-HC-65233), University of Miami (HHSN268201300004I / N01-HC-65234), Albert Einstein College of Medicine (HHSN268201300002I / N01-HC-65235), University of Illinois at Chicago - HHSN268201300003I / N01-HC-65236 Northwestern Univ), and San Diego State University (HHSN268201300005I / N01-HC-65237). The following Institutes/Centers/Offices have contributed to the HCHS/SOL through a transfer of funds to the NHLBI: National Institute on Minority Health and Health Disparities, National Institute on Deafness and Other Communication Disorders, National Institute of Dental and Craniofacial Research, National Institute of Diabetes and Digestive and Kidney Diseases, National Institute of Neurological Disorders and Stroke, NIH Institution-Office of Dietary Supplements

MLR was supported by NIDDK/NIH 2T32DK007750-20

Authors' contributions: MLR- Conception/design, analysis and interpretation of data, drafting and revising; LRLConception/design, interpretation of data, revising; SLH- Conception/design, interpretation of data, revising; $\mathrm{YH}$ analysis and interpretation of data, revising; CRI- interpretation of data, revising; CC- interpretation of data, revising; ACR- interpretation of data, revising; JPL- interpretation of data, revising; VKD- Conception/design, interpretation of data, drafting and revising. All authors read and approved the final manuscript.

Acknowledgements: The authors thank the HCHS/SOL staff and participants for their important contributions. A complete list of staff and investigators is available on the study website http://www.cscc.unc.edu/hchs/

\section{References}

1. Williams D, Davison J. Chronic kidney disease in pregnancy. BMJ. 2008;336(7637):211-5.

2. Schmidt RJ, Holley JL. Fertility and contraception in end-stage renal disease. Adv Ren Replace Ther. 1998;5(1):38-44.

3. Holley JL, Schmidt RJ. Changes in fertility and hormone replacement therapy in kidney disease. Adv Chronic Kidney Dis. 2013;20(3):240-5.

4. Palmer BF, Clegg DJ. Gonadal dysfunction in chronic kidney disease. Rev Endocr Metab Disord. 2017;18(1):11730.

5. Holley JL, Schmidt RJ, Bender FH, Dumler F, Schiff M. Gynecologic and reproductive issues in women on dialysis. Am J Kidney Dis. 1997;29(5):685-90.

6. Lim VS, Henriquez C, Sievertsen G, Frohman LA. Ovarian function in chronic renal failure: evidence suggesting hypothalamic anovulation. Ann Intern Med. 1980;93(1):21-7.

7. Hou SH, Grossman S, Molitch ME. Hyperprolactinemia in patients with renal insufficiency and chronic renal failure requiring hemodialysis or chronic ambulatory peritoneal dialysis. Am J Kidney Dis. 1985;6(4):245-9.

8. Manisco G, Poti M, Maggiulli G, Di Tullio M, Losappio V, Vernaglione L. Pregnancy in end-stage renal disease patients on dialysis: how to achieve a successful delivery. Clin Kidney J. 2015;8(3):293-9.

Page $12 / 17$ 
9. Metwally M, Ledger WL, Li TC. Does high body mass index increase the risk of miscarriage after spontaneous and assisted conception? A meta-analysis of the evidence. Fertil Steril. 2008;90(3):714-26.

10. McGrogan A, Snowball J, de Vries CS. Pregnancy losses in women with Type 1 or Type 2 diabetes in the UK: an investigation using primary care records. Diabetic Med. 2014;31(3):357-65.

11. Nobles CJ, Mendola P, Mumford SL, Naimi Al, Yeung EH, Kim K, et al. Preconception Blood Pressure Levels and Reproductive Outcomes in a Prospective Cohort of Women Attempting Pregnancy. Hypertension. 2018;71(5):90410.

12. Jesudason S, Grace BS, McDonald SP. Pregnancy outcomes according to dialysis commencing before or after conception in women with ESRD. Clin J Am Soc Nephrol. 2014;9(1):143-49.

13. Benabe JE, Rios EV. Kidney disease in the Hispanic population: facing the growing challenge. J Natl Med Assoc. 2004;96(6):789-98.

14. Desai N, Lora CM, Lash JP, Ricardo AC. CKD and ESRD in US Hispanics. Am J Kidney Dis. 2019;73(1):102-11.

15. Saran R, Robinson B, Abbott KC, Agodoa LY, Albertus P, Ayanian J, et al. US Renal Data System 2016 Annual Data Report: Epidemiology of Kidney Disease in the United States. Am J Kidney Dis. 2017;69(3 Suppl 1):A7-A8.

16. Fischer MJ, Hsu JY, Lora CM, Ricardo AC, Anderson AH, Bazzano L, et al. CKD Progression and Mortality among Hispanics and Non-Hispanics. J Am Soc Nephrol. 2016;27(11):3488-97.

17. Ricardo AC, Flessner MF, Eckfeldt JH, Eggers PW, Franceschini N, Go AS, et al. Prevalence and Correlates of CKD in Hispanics/Latinos in the United States. Clin J Am Soc Nephrol. 2015;10(10):1757-66.

18. Rossen LM, Ahrens KA, Branum AM. Trends in Risk of Pregnancy Loss Among US Women, 1990-2011. Paediatr Perinat Epidemiol. 2018;32(1):19-29.

19. Healy AJ, Malone FD, Sullivan LM, Porter TF, Luthy DA, Comstock CH, et al. Early access to prenatal care: implications for racial disparity in perinatal mortality. Obstet Gynecol. 2006;107(3):625-31.

20. Farren J, Jalmbrant M, Falconieri N, Mitchell-Jones N, Bobdiwala S, Al-Memar M, et al. Posttraumatic stress, anxiety and depression following miscarriage and ectopic pregnancy: a multicenter, prospective, cohort study. Am J Obstet Gynecol. 2020;222(4):367 e1- e22.

21. Lavange LM, Kalsbeek WD, Sorlie PD, Aviles-Santa LM, Kaplan RC, Barnhart J, et al. Sample design and cohort selection in the Hispanic Community Health Study/Study of Latinos. Ann Epidemiol. 2010;20(8):642-9.

22. Sorlie PD, Aviles-Santa LM, Wassertheil-Smoller S, Kaplan RC, Daviglus ML, Giachello AL, et al. Design and implementation of the Hispanic Community Health Study/Study of Latinos. Ann Epidemiol. 2010;20(8):629-41.

23. Levey AS, Stevens LA, Schmid CH, Zhang YL, Castro AF, 3rd, Feldman HI, et al. A new equation to estimate glomerular filtration rate. Ann Intern Med. 2009;150(9):604-12.

24. Cousineau TM, Domar AD. Psychological impact of infertility. Best Pract Res Clin Obstet Gynaecol. 2007;21(2):293-308.

25. Muka T, Oliver-Williams C, Kunutsor S, Laven JS, Fauser BC, Chowdhury R, et al. Association of Age at Onset of Menopause and Time Since Onset of Menopause With Cardiovascular Outcomes, Intermediate Vascular Traits, and All-Cause Mortality: A Systematic Review and Meta-analysis. JAMA Cardiol. 2016;1(7):767-76.

26. Broughton DE, Moley KH. Obesity and female infertility: potential mediators of obesity's impact. Fertil Steril. 2017;107(4):840-7.

27. Livshits A, Seidman DS. Fertility issues in women with diabetes. Womens Health (Lond). 2009;5(6):701-7.

28. Cochrane R, Regan L. Undetected gynaecological disorders in women with renal disease. Hum Reprod. 1997;12(4):667-70. 
29. Kramer HM, Curhan GC, Singh A. Hemodialysis, Estrogen Levels in Postmenopausal Patients Study G:

Permanent cessation of menses and postmenopausal hormone use in dialysis-dependent women: the HELP study. Am J Kidney Dis. 2003;41(3):643-50.

30. Cheung KL, Stefanick ML, Allison MA, LeBlanc ES, Vitolins MZ, Shara N, et al. Menopausal symptoms in women with chronic kidney disease. Menopause. 2015;22(9):1006-11.

31. Regan L, Rai R. Epidemiology and the medical causes of miscarriage. Baillieres Best Pract Res Clin Obstet Gynaecol. 2000;14(5):839-54.

32. Wang X, Chen C, Wang L, Chen D, Guang W, French J. Conception, early pregnancy loss, and time to clinical pregnancy: a population-based prospective study. Fertil Steril. 2003;79(3):577-84.

33. Asamiya Y, Otsubo S, Matsuda Y, Kimata N, Kikuchi KAN, Miwa N, et al. The importance of low blood urea nitrogen levels in pregnant patients undergoing hemodialysis to optimize birth weight and gestational age. Kidney Int. 2009;75(11):1217-22.

34. Josephson MA, McKay DB. Women and transplantation: fertility, sexuality, pregnancy, contraception. Adv Chronic Kidney Dis. 2013;20(5):433-40.

35. Gill JS, Zalunardo N, Rose C, Tonelli M. The pregnancy rate and live birth rate in kidney transplant recipients. Am J Transplant. 2009;9(7):1541-9.

36. Shah S, Venkatesan RL, Gupta A, Sanghavi MK, Welge J, Johansen R, et al. Pregnancy outcomes in women with kidney transplant: Metaanalysis and systematic review. BMC Nephrol. 2019;20(1):24.

37. Webster P, Lightstone L, McKay DB, Josephson MA. Pregnancy in chronic kidney disease and kidney transplantation. Kidney Int. 2017;91(5):1047-56.

38. Halbesma N, Kuiken DS, Brantsma AH, Bakker SJ, Wetzels JF, De Zeeuw D, et al. Macroalbuminuria is a better risk marker than low estimated GFR to identify individuals at risk for accelerated GFR loss in population screening. J Am Soc Nephrol. 2006;17(9):2582-90.

39. Hemmelgarn BR, Manns BJ, Lloyd A, James MT, Klarenbach S, Quinn RR, et al. Relation between kidney function, proteinuria, and adverse outcomes. JAMA. 2010;303(5):423-9.

40. Gansevoort RT, Matsushita K, van der Velde M, Astor BC, Woodward M, Levey AS, et al. Lower estimated GFR and higher albuminuria are associated with adverse kidney outcomes. A collaborative meta-analysis of general and high-risk population cohorts. Kidney Int. 2011; 80(1):93-104.

41. Horn J, Tanz LJ, Stuart JJ, Markovitz AR, Skurnik G, Rimm EB, et al. Early or late pregnancy loss and development of clinical cardiovascular disease risk factors: a prospective cohort study. BJOG. 2019;126(1):3342.

42. American College of O, Gynecologists Committee on Gynecologic P, Practice C. Female age-related fertility decline. Committee Opinion No. 589. Fertil Steril. 2014;101(3):633-4.

\section{Figures}




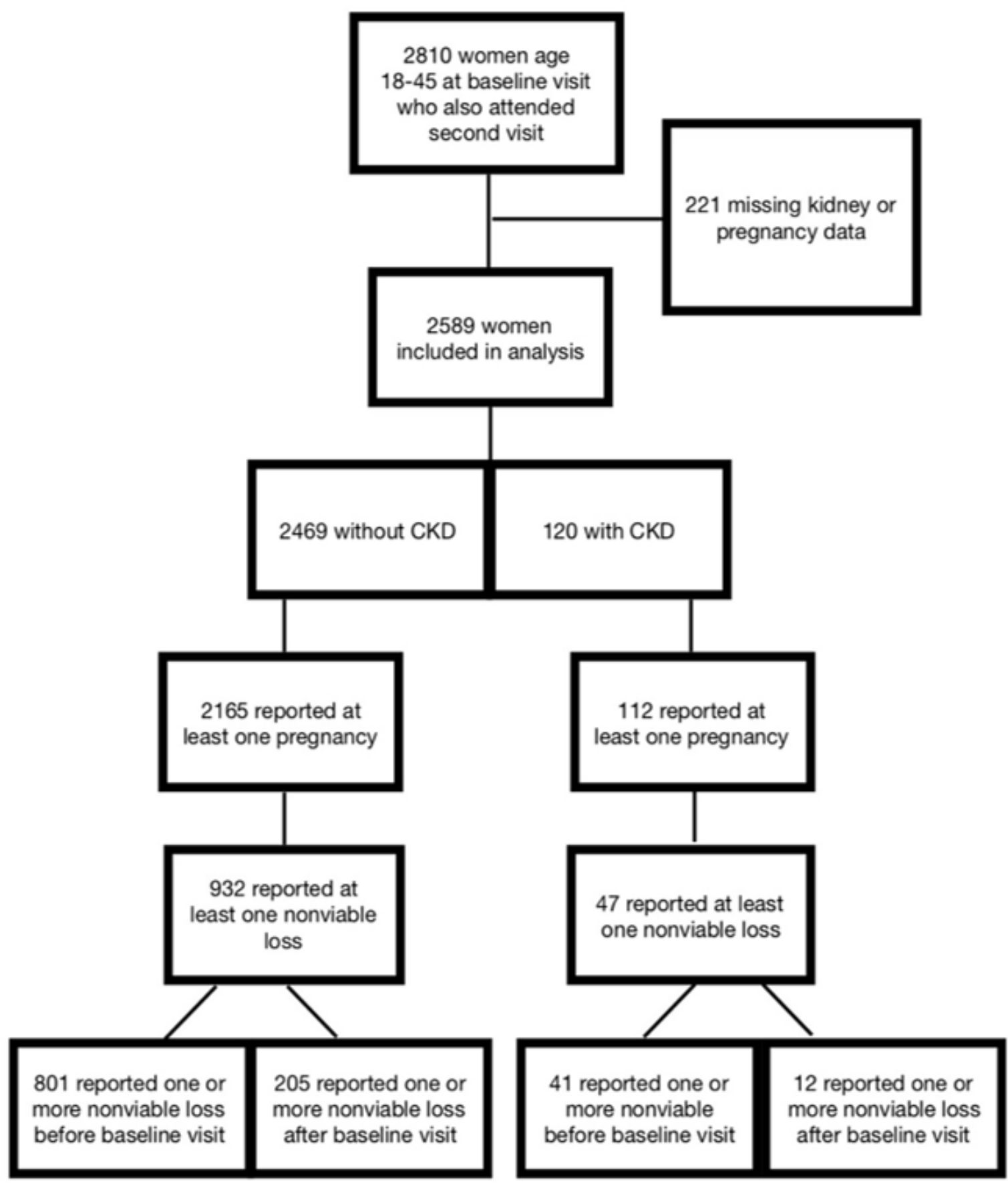

Figure 1

Participant Inclusion and Pregnancies Reported by Reproductive Age Women With and Without CKD at the HCHS/SOL Second Study Visit (2014-2017). Abbreviations: CKD, chronic kidney disease; HCHS/SOL, Hispanic Community Health Study, Study of Latinos 


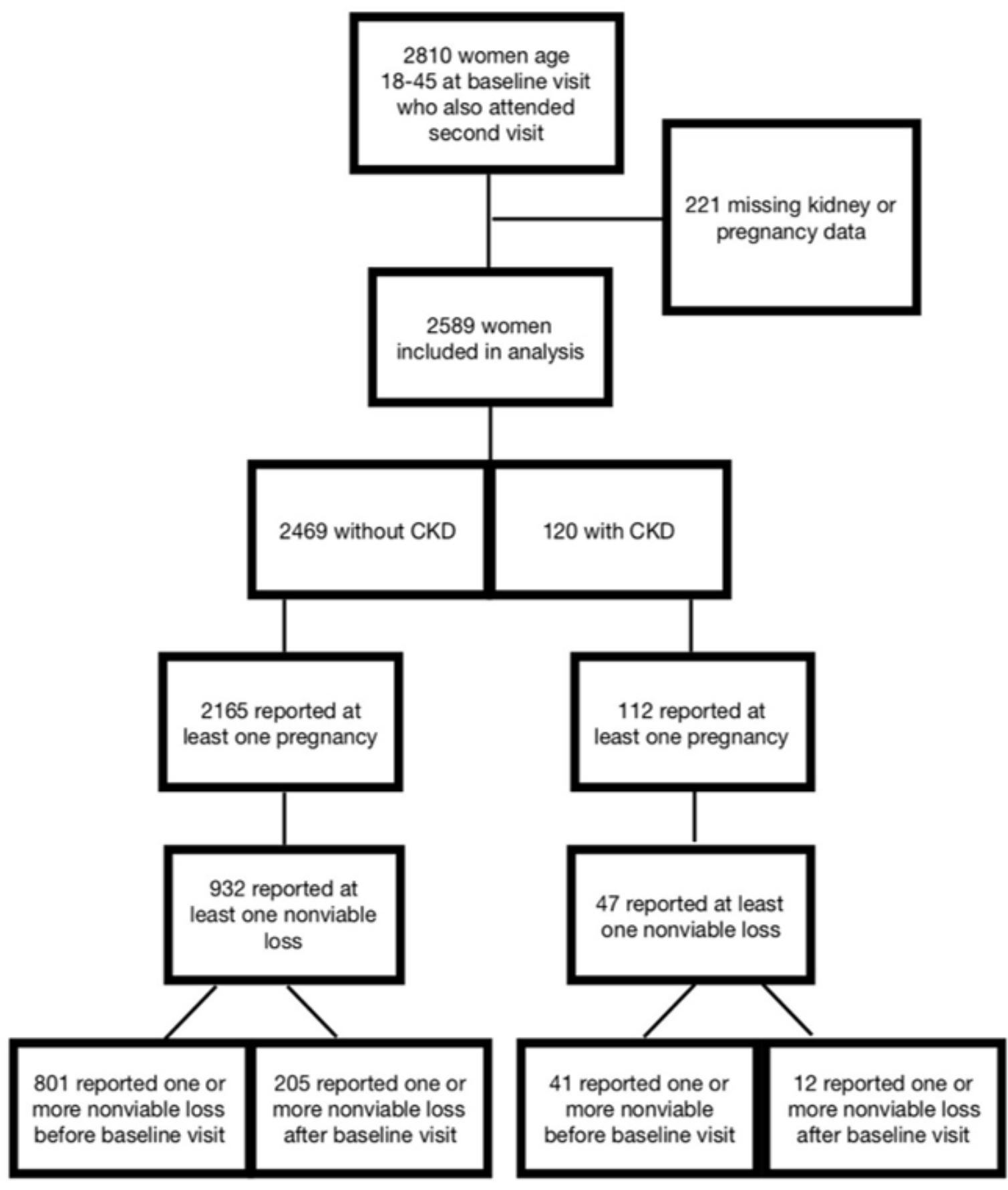

Figure 1

Participant Inclusion and Pregnancies Reported by Reproductive Age Women With and Without CKD at the HCHS/SOL Second Study Visit (2014-2017). Abbreviations: CKD, chronic kidney disease; HCHS/SOL, Hispanic Community Health Study, Study of Latinos

\section{Supplementary Files}

This is a list of supplementary files associated with this preprint. Click to download.

- RMEReproandMedicalHx952014.pdf

- RMEReproandMedicalHx952014.pdf 
- PCEPregnancyComplicationsHx952014.pdf

- PCEPregnancyComplicationsHx952014.pdf 